\title{
Urban Thermal Field Mining Using Remote Sensing Images
}

\author{
Shiqiang Zhou ${ }^{1}$, Lan Liu ${ }^{1}$, Chengfan $\mathrm{Li}^{1}$, a , Jingyuan Yin ${ }^{2, \mathrm{~b}}$ \\ ${ }^{1}$ School of Computer Engineering and Science, Shanghai University, Shanghai 200444, China \\ ${ }^{2}$ Earthquake Administration of Shanghai Municipality, Shanghai 200062, China \\ aemail: Ichf@shu.edu.cn, bemail: jyyin@staff.shu.edu.cn
}

\begin{abstract}
Keywords: Remote Sensing; Data Mining; Urban Thermal Field; Shanghai
\end{abstract}
\begin{abstract}
Information mining of urban thermal field is the key in the study of the urban public security and sustainable development. The moderate-resolution imaging spectroradiometer (MODIS) remote sensing images in 2010 were used to mine the urban thermal field information with the mono window algorithm; furthermore, the relationship between urban thermal field and urban construction land was analyzed. The experimental results show that: (1) the urban thermal field's intensity in September is at its maximum, following is August and July, the others obviously weaker than in the above three months. (2) the urban construction land has the biggest contribution to the urban thermal field in Shanghai area, and there is a closely relationship between the urban construction land and the urban thermal field.
\end{abstract}

\section{Introduction}

Urban thermal field is an inevitable trend of urbanization with the development of human society. Generally speaking, the urban thermal field means the phenomena of urban heat island effect[1]. In recent years, due to the dense urban buildings, severe traffic congestion, air pollution, and the buildings in the city are mostly concrete, high conductivity and heat capacity, the urban thermal field has become more and more remarkable, and it greatly exacerbates the elevation of the urban temperature. The urban thermal field first appeared in the early 19th century urban climate research in London[2]. At present, the impact of urban thermal field on global warming has caused much attention, and a serious delightful fruits are achieved. For example, the formation of the urban thermal field is mainly affected by urban land use, urban air pollution, artificial heat source, vegetation cover, population density[3,4]. Thermal infrared remote sensing can mine effectively the urban thermal field information, and make up disadvantage of the traditional urban thermal field mining methods. At present, the most common remote sensing image used in the mining urban thermal field is moderate-resolution imaging spectroradiometer (MODIS). So far, the mining method using remote sensing often includes atmospheric correction method, mono window algorithm[5,6], ubiquitous mono window algorithm[7], split window algorithm[8], multi-band algorithm and multi-angle algorithm, etc. Mono window algorithm mainly inverse the band ground brightness temperature using thermal infrared band, it is simple and easy to implement, and more widely used in practical applications.

Shanghai is the largest city, the biggest economic and financial center in China, and also is the core of the Yangtze River region which is the China's most economically developed regions (see Figure 1). With the recent rapid development of economy and opening up of Pudong New Area in Shanghai, it causes a series of urban ecological environmental issues, such as the urban thermal field, water and air pollution, etc. This paper takes the Shanghai area, China for example, using the MODIS remote sensing images in 2010, to mine the urban thermal field. Following this introduction, we'll devote the second sections briefly describing the mono window algorithm; Second, analysis Shanghai's urban thermal field mining of the different months in the 2010; Third, we derive the relationship between urban thermal field and land use structure in Shanghai; We conclude our study with summary and future study foci in the last section. 


\section{Mono window algorithm}

The brightness values $(B V)$ of the urban thermal field based on MODIS thermal infrared images should be converted into radiance $(L)$ before urban thermal field mining. The formula is shown below $[9,10]$ :

$$
L=L_{\min }+\left(L_{\max }-L_{\min }\right) \times B V / 255
$$

where $L_{\max }$ is the biggest radiance that sensor is able to detect and $L_{\max }=1.56 \mathrm{~W} / \mathrm{Sr} \cdot \mathrm{m}^{2}, L_{\min }$ is the smallest radiance and $L_{\min }=0.1238 \mathrm{~W} / \mathrm{Sr} \cdot \mathrm{m}^{2}, B V$ is the brightness value of thermal infrared image. The star brightness temperature $T$ can be calculated by the formula $T=K_{1} / \ln \left(\mathrm{K}_{2} / \mathrm{L}+1\right)$, where $K_{1}$ and $K_{2}$ are calibration parameters, and $K_{1}=1260.56 \mathrm{~W} / \mathrm{m}^{2} \cdot$ ster $\cdot \mu \mathrm{m}, K_{2}=607.76 \mathrm{~K}$.

The urban thermal field mining was carried out. The specific calculation procedure is as follows:

$$
T_{s}=\left\{a(1-C-D)+[b(1-C-D)+C+D] T-D T_{\mathrm{a}}\right\} / C
$$

where $T_{s}$ is the true ground temperature, $T$ is the brightness temperature measured by satellite sensors, $T_{a}$ is the equivalent average atmospheric temperature, $a$ and $b$ are the regression coefficients, respectively, and $a=-67.355351, b=0.458606, C$ and $D$ are intermediate variables, respectively, and $C=\tau \varepsilon, D=(1-\tau)[1+\tau(1-\varepsilon)](\tau$ is the atmospheric transmittance, $\varepsilon$ is the surface emissivity).

The equivalent average atmospheric temperature $T_{a}$ can be expressed as follows:

$$
T_{a}=17.9769+0.91715 \times T_{0}
$$

where $T_{0}$ is the near-surface atmospheric temperature, its unit is $\mathrm{K}$.

The atmospheric transmittance $\tau$ can be expressed as follows:

$$
\tau=\left\{\begin{array}{cc}
0.974290-0.08007 \omega & (0.4<\omega<1.6) \\
1.031412-0.11536 \omega & (1.6 \leq \omega<3.0)
\end{array}\right.
$$

where $\omega$ is the water vapor content in the atmosphere, its unit is $\mathrm{g} / \mathrm{cm}^{2}$.

The surface emissivity $\varepsilon$ can be expressed as follows:

$$
\varepsilon=0.9625+0.0614 P-0.0461 P \times P
$$

where $P$ is the vegetation coverage, it represents the growth conditions of vegetation.

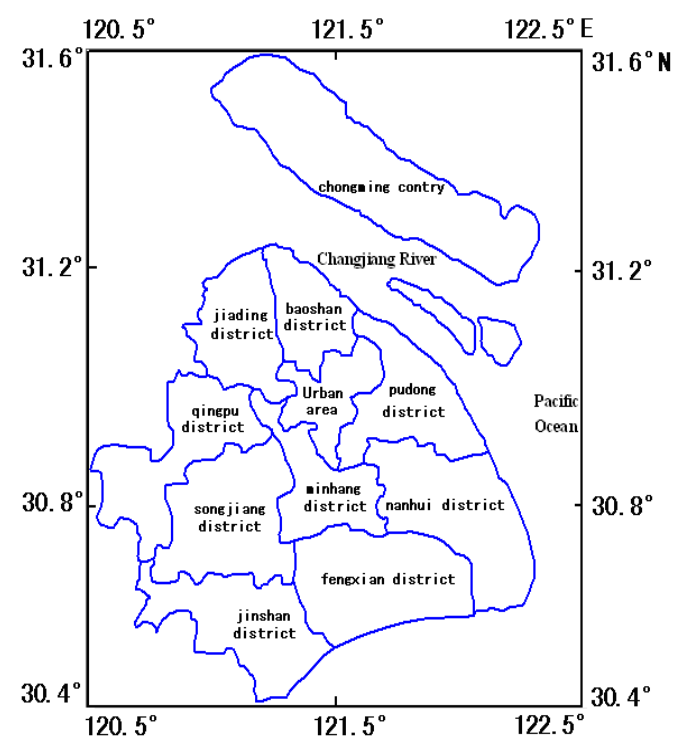

Fig.1. Geographical location of Shanghai area

\section{Urban thermal field mining from MODIS images}

In order to better analyze the characteristics in different months of the urban thermal field in Shanghai area in 2010, in this paper, the urban thermal field's characteristics have been mined by mono window algorithm based on MODIS remote sensing images. Depending on the actual 
situation of Shanghai area, the urban thermal field is grading classified into 10 levels (see Figure 2).

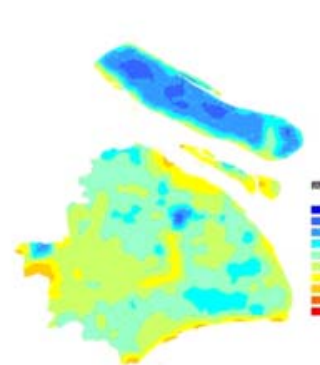

(a)

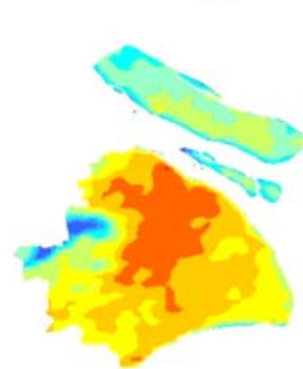

(d)

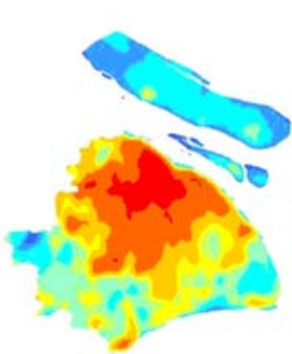

(g)

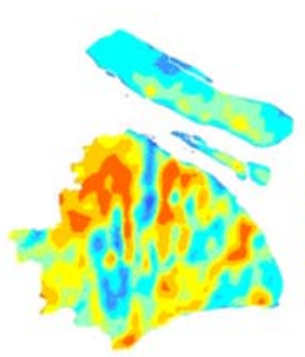

(j)
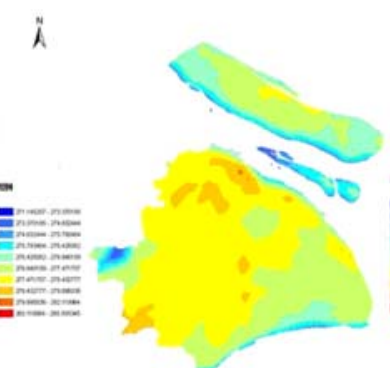

(b)

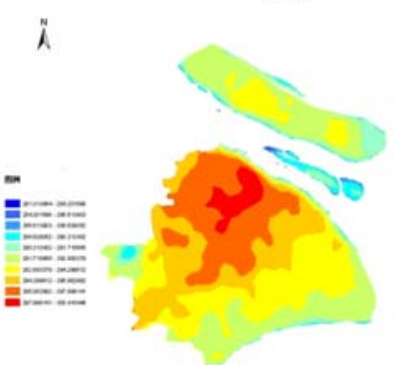

(e)

$$
\text { i }
$$
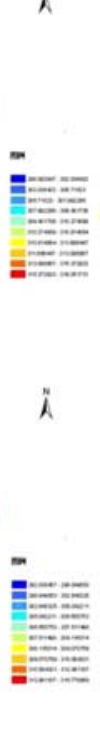

i

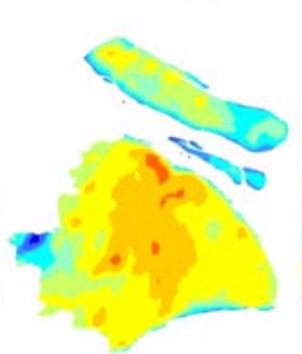

(k)
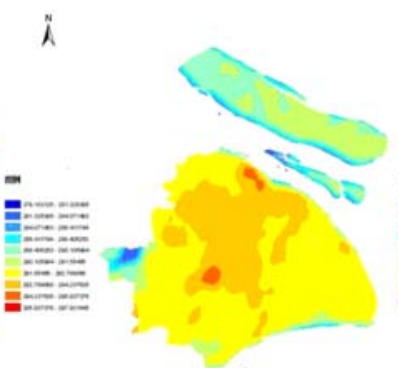

(c)
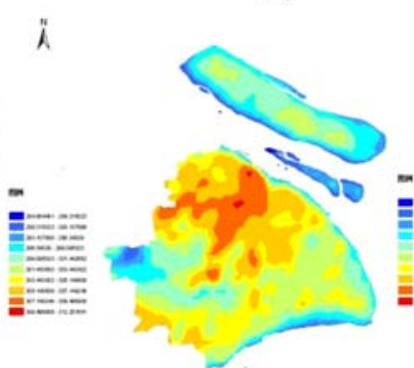

(f)
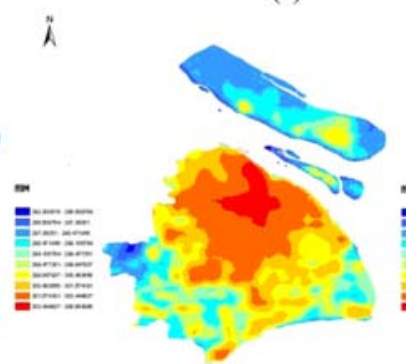

(i)

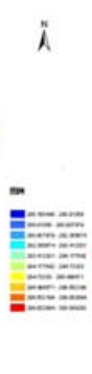

i

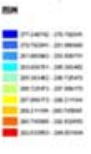

i

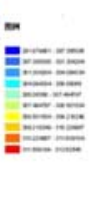

i

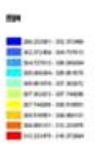

Fig.2. Urban thermal field monthly in 2010 , a- -1 is January-December respectively

As can be seen from Figure 2, the intensity of Shanghai's urban thermal field in September is at its maximum; following is August and July, the intensity of Shanghai's urban thermal field in other month obviously weaker than in the above three months. In the September, the most significant areas of the intensity in Shanghai area are mainly located in the northern regions (especially in Baoshan District) and Shanghai downtown area. Similarly, the most significant areas of urban thermal field intensity in August and July are also mainly located in the Baoshan District and Shanghai downtown. The urban thermal field intensity of other months is significantly weaker than in summer season. This is also consistent with the previous research conclusions[9,10], the urban thermal field is higher in summer and fall season, it is lower in winter and spring season.

\section{Relationship between urban thermal field and land use structure}

In general, the urban thermal field's formation is largely caused by the expansion of urban construction land. The urban construction land made the biggest contribution to urban thermal field in different land use structure, and the green land and water area made a small contribution. In addition, the most typical land use structure in Shanghai area is urban construction land, in the next, 
the urban land construction information was extracted by the supervised classification method based on the MODIS image in 2010. And then the relationship between the urban construction land and the urban thermal field was analysis.

The obtained urban land use structure map of Shanghai area from MODIS image in 2010 is shown in Figure 3(a). Thereinto, the classification accuracy assessment of thematic information was implemented by random sampling method, and the results show that the classification accuracy reached $91.5 \%$. It has made a better classification results and can meet the needs of practical application.

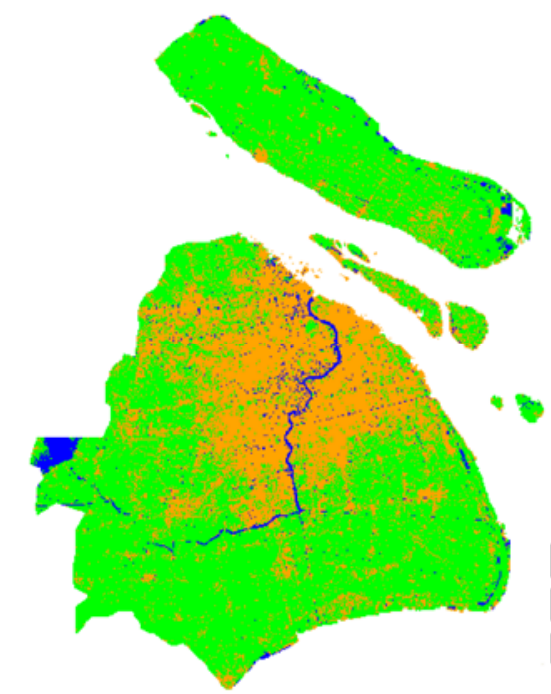

(a) Urban land use structure

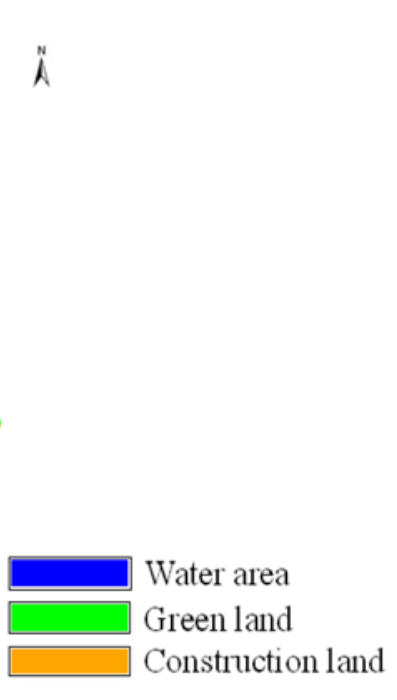

(b) Contour map of urban thermal field

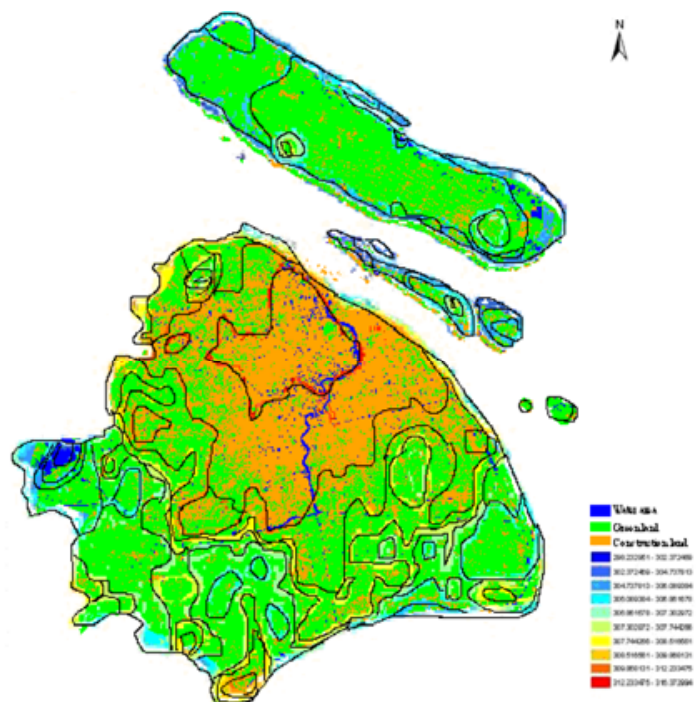

Fig.3. Relationship between UHI effect and urban land use structure of Shanghai in 2010

Next, in order to obtain the relationship between the urban thermal field and land use structure in Shanghai area, the urban thermal field's intensity in September, 2010 is transformed into the contour map of the thermal field, and superimposed on the urban land use structure of Shanghai area has already acquired previously. The result is shown in Figure 3(b).

As can be seen from Figure 3(b), strong urban thermal field areas in 2010 are basically consistent with the urban construction land area; Coastal areas and Chongming County has a lower urban thermal field's intensity; the southern suburb including Songjiang District, Fengxian District and Jinshan District has lower urban thermal field's intensity. This is also consistent with the actual geographic distribution in Shanghai area. Chongming County is facing the East China Sea and Yangtze River, Fengxian District and Jinshan District are facing the East China Sea and Hangzhou Bay, and has good vegetation cover situation. What's more, it also proved once again that there is a closely relationship between the urban construction land and the urban thermal field.

\section{Conclusion}

In light of mining urban thermal field of Shanghai area in 2010 with MODIS remote sensing images, this paper analysis the relationship between the urban land use structure and the urban thermal field (especially the construction land), and has the following meaningful conclusions: on the one hand, the urban thermal field's intensity in September is at its maximum, following is August and July. On the other hand, there is a closely relationship between the urban construction land and the urban thermal field in Shanghai area. Although some of significant conclusions were obtained, there are still a few problems during the research, and these have yet to be further discussion and study in the future.

\section{Acknowledgement}

This work was co-supported by the National Science Foundation of China (Project No. 41404024), Shanghai Science and Technology Development Foundation (Project No. 14231202600) 
and Young Teachers Training and Supporting Plan in Shanghai Universities (Project No. 2014-2016). The authors gratefully acknowledge this supports.

\section{References}

[1] Chen XL, Zhao HM, Li PX, Yin ZY. Remote sensing image-based analysis of the relationship between urban heat island and land use/cover changes[J]. Remote Sensing of Environment, 2006, 104(2):133-146.

[2] Sandholt I, Rasmussen K, Andersen J. A simple interpretation of the surface temperature/vegetation index space for assessment of surface moisture[J]. Remote Sensing of Environment, 2002, 79(2-3):213-224.

[3] Yuan F, Bauer ME. Comparison of impervious surface area and normalized difference vegetation index as indicators of surface urban heat island effects in Landsat imagery[J]. Remote Sensing of Environment, 2007, 106(3):375-386.

[4] Zha Y, Gao J, Ni S. Use of normalized difference built-up index in automatically mapping urban areas from TM imagery[J]. International Journal of Remote Sensing, 2003, 24(3):583-594.

[5] Qin ZH, Kernieli A, Berliner P. A mono-window algorithm for retrieving land surface temperature from Landsat TM data and its application to the Israel-Egypt border region[J]. International Journal of Remote Sensing, 2001, 22(18):3719-3746.

[6] Qin ZH, Dall'Olmo G, Karnieli A. Derivation of split window algorithm and its sensitivity analysis for retrieving land surface temperature from NOAA-AVHRR data[J]. Journal of Geophysical Research, 2001, 106(D19):22655-22670.

[7] Jimenez-Munoz JC, Sobrino JA. A generalized single channel method for retrieving land surface temperature from remote sensing data[J]. Journal of Geophysical Research, 2003, 108(D22): 21-29.

[8] Chen MN, Zhang H, Tang JY, Chen WZ, Zhang Y, Ma C. Study on the thermal environment of land surface in shanghai with multi-temporal remote sensing images[J]. China Environmental of Science, 2011, 31(7):1143-1151.

[9] Li CF, Yin JY. A study on urban thermal field of Shanghai using multi-source remote sensing data[J]. Journal of the Indian Society of Remote Sensing, 2013, 41(4): 1009-1019.

[10] Li CF, Shen D, Dong JS, Yin JY, Zhao JJ, Xue D. Monitoring of urban heat island in Shanghai, China, from 1981 to 2010 with satellite data[J].Arabian Journal of Geoscience, 2014, 7(10): 3961-3971. 